\title{
Quality Management System Is a Change Management Process
}

\author{
By Dr. Omer El Tigani \\ Quality Manager, Tanween Co.
}

Introduction - Having a successful Quality Management System is a very hard job and requires all parties within the organization to work as one hand and all to push in one direction. This is why only few organizations around the globe who managed to go in a successful Quality Journey and get benefited from its enormous advantages. From experience, the Author believes that one of the most effective methodologies for the organization to follow (for a successful Quality Journey) is to approach it as a complete Change Management Process. In the following part, the Author tries to provide the organization with some suggestions for activities or actions to do in light of Kurt Lewin's Change Model.

GJMBR-A Classification : FOR Code : 150313 JEL Code: 015

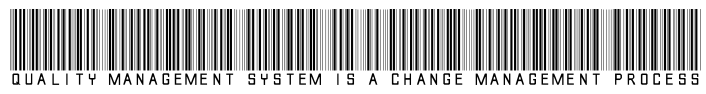

Strictly as per the compliance and regulations of:

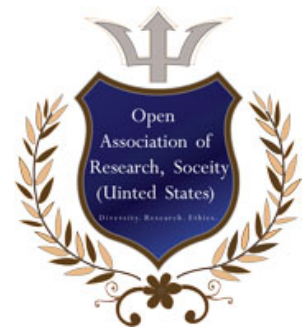

(C) 2011. Dr. Omer El Tigani.This is a research/review paper, distributed under the terms of the Creative Commons AttributionNoncommercial 3.0 Unported License http://creativecommons.org/licenses/by-nc/3.0/), permitting all non-commercial use, distribution, and reproduction in any medium, provided the original work is properly cited. 


\title{
Quality Management System Is a Change Management Process
}

\author{
Dr. Omer El Tigani
}

\section{INTRODUCTION}

H aving a successful Quality Management System is a very hard job and requires all parties within the organization to work as one hand and all to push in one direction. This is why only few organizations around the globe who managed to go in a successful Quality Journey and get benefited from its enormous advantages. From experience, the Author believes that one of the most effective methodologies for the organization to follow (for a successful Quality Journey) is to approach it as a complete Change Management Process. In the following part, the Author tries to provide the organization with some suggestions for activities or actions to do in light of Kurt Lewin's Change Model.

\section{What IS QUALiTy MANAGEMENT SYSTEM?}

Quality Management System (QMS) is a set of interrelated processes that designed to operate to produce products or present services required to meet stakeholders' desires. One or more processes are documented in one Procedures, Work Instructions or Guidelines. Also, an important part of every successful QMS, which is ignored by so many people, is the documentation related to the maintenance and improvement of the QMS itself, such as: Internal Audits, Corrective Actions, Preventive Actions, Document Controls, Quality Objectives, and so on.

\section{QUALiTy JOURNEY}

Establishing, implementing, maintaining and continually improving the QMS is an endless Journey that the organization should go for; striving to hit theTotal Quality Management (TQM) as a destination. But, to convince the organization's top management and all workers to adopt the QMS as a journey and not to deal with it as a project with a definite end; is a huge challenge for the Quality Management Team. Moreover, applying a proper change management process is another big challenge.

\section{Change MAnAgement}

Change is inevitable for every successful organization to experience at different points during its

Author: Quality Manager, Tanween Co.

E-mail:omeraaziz@hotmail.com development. Upon the announcement of the top management that the organization embarked on its journey towards Total Quality Management and Business Excellence, a very challenging change process will instigate. Managing the change process is crucial for the success of the QMS. The change agent or the leader of the change is responsible to properly manage the change. When we say "manage", that means the change leader/agent has to tackle all management elements, like: planning, organizing, monitoring, assessing, communicating, motivating, and so on. It's very important to understand that organizational change not only relating to structure, apply new technology, implement new management system; but also it should involve cultural and behavioral changes to all organizational level, including the individual ones.

Kurt Lewin similarly described the Change Process as a Journey with no definite end. He split the change process into three phases: i) Un-freezing, ii) Moving and iii) Re-freezing (Hitt, Porter \& Black, 2004, p. 47). Although this theory was originally presented in 1947, but the Kurt Lewin's change model is still relevant. In the following part we will discuss the ideal actions and/ oractivities that any new QMS should do to ensure a good implementation of Lewin's Change Phases. We will also discuss in detail what the organization should do in each phase to have successful and fruitful Quality Journey at the end. Of course, the time and resources needed for the successful implementation of the ISO Quality Management System (QMS) differs from organization to another; it mainly depends upon so many factors, such as: a) the size of the organization; b) the complexity of the existing management system and the associated processes; c) the distance of the current organizations' system and culture from those desired.

\section{Phase (I) : Un-FreEZING}

This phase is the most important phase, as it represents the trigger of the Change Management Process. In this phase the organization recognizes the need for change and that the current system, structure, technology is not feasible anymore and Chang is necessary. The importance of this phase comes from that the recognition and definition of the problem is or more than the half-way of achieving the desired results and/or getting the problem solved. Therefore, the more 
that the organization feels the change is necessary, the more that the change desired is priority and the more that the organization is enthusiastic and motivated to successfully achieve the desired change results.

\section{a) Identify Change Drivers}

First of all and the foremost, the top management of the organization (i.e. top management covers all of the senior management team members) must be fully convinced by that the new Quality Management System will definitely improve the overall performance of the organization, enhance its image and position in the marketplace and assist in satisfying its stakeholders. Upon the success of this, top management of the organization must reveal a commitment to the establishment, implementation preservation and continual improvement of the Quality Management System in the organization.

As a result of their commitment, top management shall appoint one person from the top management members of the organization to be the Change Agent, who irrespective of his/her other responsibilities, shall have responsibilities and authorities related to the quality management system, which includes: (a) ensuring that processes needed for the quality management system are established, implemented and maintained, (b) reporting to top management on the performance of the quality management system and any need for improvement, and (c) ensuring the promotion of awareness of customer requirements throughout the organization. (ISO, 2008)

Because of his/her crucial role in the success of the new QMS, the Management Representative (i.e. the Change Agent) should be carefully selected among the top management members. He/She must have, but not limited to, the following characteristics:

- High interpersonal skills;

- High leadership skills;

- Strong personality;

- Ability to build positive relationships with top management and other employees, i.e. the lesser number of enemies he/she has, the greater people involvement the organization's QMS will gain;

- Knowledgeable about Quality Principles and concepts (e.g. ISO 9001:2008 requirements, Excellence Model criteria, etc.);

In addition to the top management member (i.e. the Change Agent), the top management should also prove their commitment by identifying the Quality Governance Committee (i.e. the Change Team), in accordance to the following:

- Consists of one or two staff members from each department.

- Selected members should be self-motivated and enthusiastic to the adoption of the QMS.

- Selected members should be knowledgeable about all or most of operations running in their departments.
Selected members preferred to be senior staff in their department, so that the organization can get benefit from their positions' influences.

- Selected members are preferred to possess leadership skills and strong personalities.

- Selected members must be well trained or at least have a reasonable background on Quality Management.

\section{b) Arrange for Minimum Resistance}

People always afraid and resist new and unclear things. To clear the ambiguity and uncertainty, a thorough and intensive awareness programs must be held, such as: lectures, seminars, workshops, exhibitions, formal and informal meetings and the like. The awareness programs can be conducted by the Change Agent, Quality Governance Committee member(s), and/or an outsourced expert(s). The main purpose of the awareness programs is to communicate to all employees at the different organizational levels (a) the aim of the Quality Management System; (b) why is it necessary? (c) the advantage it offers to theorganization and all stakeholders (including the employees); (d) how it will work; and (e) their roles and responsibilities within the QMS. Employees' awareness will also pave the way for the achievement of the "People Involvement", which is an important principle of the eight Quality Management Principles, i.e. the eight pillars that any successful QMS should construct.

Some sort of reward/punishment systems linked to the performance of the QMS tasks should be established and applied to all employees according to: (a) their cooperation with the Management Representative and the Quality Governance Committee; (b) quality of the performed jobs/tasks; (c) their commitment and meeting deadlines; (d) their initiation and innovative contributions; and (e) so many other criteria related to the QMS for rewarding/punishing employees.

\section{PhASE (II) : MOVING}

This second phase occurs when the needed changes are made. In this phase, people are 'unfrozen' and moving towards the desired changes. Definitely, it's not an easy time for people to exactly understand the changes, therefore, people must be supported by huge efforts to be made in communicating the clear picture of the desired changes, awareness, training and design a proper system to correct mistakes that may take place at this stage. Some actions are recommended to be taken by the organization during this phase to ensure a successful and smooth moving process in its Quality Journey. For a smooth moving phase, the organization should initially identify the gap or the empty spaces between the existing quality management system of the organization and the quality management system required by the targeted international standard (e.g. ISO 9001:2008 Standard requirements). So, the next 
step is to compare the organization's existing quality management system, if any, with the requirements of the targeted international standard. The outcome of this step is a report exactly determining the gaps between the existing quality management system of the organization and that required by the targeted international standard as well as proposing the most suitable actions, activities and/or processes to fulfill those gaps.

\section{a) How to Move Towards the Desired QMS}

It's important to mention that the action of gap analysis is not only related to identifying gaps for meeting requirements of a certain international standard or quality certification/accreditation, but also, it can be conducted to diagnose or identify what actions and documentation (e.g. processes, procedures, documents, etc.) need to be performed to meet some stakeholders' requirements internally (e.g. internal processes, internal customers, internal suppliers, etc.)or externally (e.g. external customers, society, governments, etc.).

By considering the findings of the Gap Analysis Report, the organization obtains a clear picture of how its current quality management system compares with the desired QMS. Then, the organization sets an action plan showing the necessary activities that should be done to establish, implement, maintain and continually improve the Quality Management System. The plan should define the responsibilities of the different departments and personnel and set target dates for the completion of activities. But there is a question now; does the $100 \%$ completion of the action plan means that the organization's QMS is complete??

The answer is of course 'NO'. The proper implementation of the developed QMS documents is the most important part in the Quality Journey. Actually, implementation of the established QMS is not an action with definite end. It's a long-term process that requires the organization to gather all its strengths and involve everybody in the organization to work hard to adapt himself/herself to the new quality management system.

The implementation of the quality management system may be by parts or may be all at once; depending upon the organization size, culture and the complexity of the processes. The most important thing to say here is that the organization must closely monitor the implementation process and update the implementation plan when necessary so as to ensure that the quality management system is effective and conforms to the desired QMS.

\section{PhASE (III) : Re-FREEZING}

From the Author's point of view, this phase is the hardest phase in the change process as it endeavors to establish stability for the changes made. Generally, this may take time according to the level of change, organization responsiveness and people enthusiasm and how they can beat their previous mental maps to achieve and maintain the change.The organization should do the best to reinforce the change and ensure that the desired change will survive. Otherwise, organization's people will go back to do what they used to do in the past. This is probably what Kurt Lewin meant by Re-freezing and supporting the desired change to make sure it continues and is not lost.

\section{a) Maintain a Healthy and Continually Improved QMS}

As mentioned before, the implementation is an ongoing process with no definite ends. So, the Author believes that the implementation process should continue and expand as an important portion of the "Refreezing" Phase. Why? I will tell you, unfortunately, most of organizations concentrate on properly establishing and implementing their operational procedures; neglecting the crucial role that the Processes and Procedures related to the QMS may play in maintaining and continually improving the established QMS. Those Processes/Procedures include, but not limited to, the following:

- Document Management and Controlling;

- Records Management and Controlling;

- Internal Quality Audits Management;

- Corrective Actions Management;

- Preventive Actions Management;

- Top Management Review;

- Managing and Controlling the Non-conforming Products/Services;

- Development and Deployment of Quality Policy;

- Development and Deployment of Quality Objectives; and/or

- Monitoring and Measurement of the Processes.

The importance of having those Processes/Procedures developed and implemented is that they ensure the effectiveness of the QMS as well as its continual improvements. For instance, the internal quality audit is one of the most effective tools that the organization uses to maintain and improve the established QMS. It's an instrument by which the organization checks out the validity, soundness and effectiveness of the implemented quality management system. During the implementation journey and specially if a certain certification or accreditation (e.g. ISO 9001:2008) is targeted, the organization conducts a number of internal quality audits in order to ensure the readiness of the organization for the Certification/Accreditation Audit, which always performed by external auditors who represents the certain certification/accreditation entity. The result of those Quality Audits always highlights the weakness areas as well as the opportunities for improvements.

\section{Vili. COnclusions}

Eventually, we can conclude that to have a successful Quality Journey, the organization must treat it as a Change Management Process; considering the Change Process Model of Mr. Kurt Lewin Model. Both 
Quality Journey and Change Journey are ongoing processes with no end. Yes, there may be lots of rest stops and many opportunities for settling down for a while; but there is no end. Therefore, the essential concept that everybody in the organization must know by heart is that Quality is a Change Process.

\section{REFERENCES RÉFÉRENCES REFERENCIAS}

1. Hitt, M., Porter, L. W. \& Black, S. (2004). Management, p. 47, first edition, Prentice Hall

2. International Organization for Standardization "ISO", 15 November 2008, Clause 5.5.2, ISO 9001 Quality Management System Requirements, fourth edition, Switzerland. 